\title{
Study of the Influence of Lead Microelement on the Process of Water Accumulation in (Phaseolus vulgaris) Plants
}

\author{
Lucia MIHALESCU ${ }^{1 *}$, Oana MARE ROSCA ${ }^{1}$, Anca DUMUTA ${ }^{1}$, Mirela CORDEA ${ }^{2}$, Zorica VOȘGAN ${ }^{1}$ \\ Technical University of Cluj-Napoca, North University Center of Baia Mare, 76 Victoriei St., \\ 430122 Baia Mare, Romania. \\ University of Agricultural Sciences and Veterinary Medicine, Cluj-Napoca, 3-5 Calea Manastur, 400372 \\ Cluj-Napoca, Romania \\ *corresponding author: luciamihalescu@yahoo.com
}

Bulletin UASVM series Agriculture 76(2) / 2019

Print ISSN 1843-5246; Electronic ISSN 1843-5386

DOI:10.15835/buasvmcn-agr: 2019.0014

\begin{abstract}
In this study our goal was to analysis the influence of different concentrations of lead on the process of water accumulation in the roots and stems of bean seedlings. In the experiments, the Borlotti variety are used. The seeds (100) were soaked in the corresponding lead acetate solutions: V1 - distilled water; V2 - 0.001\%; V3 - 0.005\%; $\mathrm{V} 4-0.01 \%$ and V $5-0.1 \%$. and were put in germinators. The roots and stems of 10 seedlings of each experimental variant were used for determining the quantity of humid and dried substance. The control had high quantity of humid substance, which proves that the water contained in the vegetal material was important for the growth of these organs. The most significant decrease was recorded at concentrations above $0.1 \%$, being highly inhibited.
\end{abstract}

Keywords: inhibition, lead acetate, seeds, stimulation

\section{Introduction}

Microelements highly influence the metabolic processes and plants growth. Even if, in plants, they are only in small quantities, the absence of one or another provokes serious disturbances in the general metabolism of plants (Boldor et al, 1981). High concentration lead negatively influences the growth, probably due to impaired absorption of oligoelements in the presence of this metal (Dobrota, 2012).

The aim of this research was to survey the influence of different concentrations of lead acetate on the quantity of humid and dried substance in the surveyed vegetative organs: roots and stems of Phaseolus. This aspect was surveyed because the specific references correlates the growth inhibition of vegetative organs with high concentrations of lead.

\section{Materials and methods}

Bean seeds of the Borlotti variety, with undetermined growth were chosen. The seeds (100) were soaked in each experimental variant: V1 - control (distilled water); V2 - 0.001\%, V3 $0.005 \%, \mathrm{~V} 4-0.01 \%$ and V5 - 0.1\% lead acetate. After 2 hours the seeds were put in Linhard type germinator, in the five variants; they were daily soaked with the corresponding solutions. Starting with the 8th day, 10 vigorous seedlings were taken from each variant; they were fixed in test tubes, 


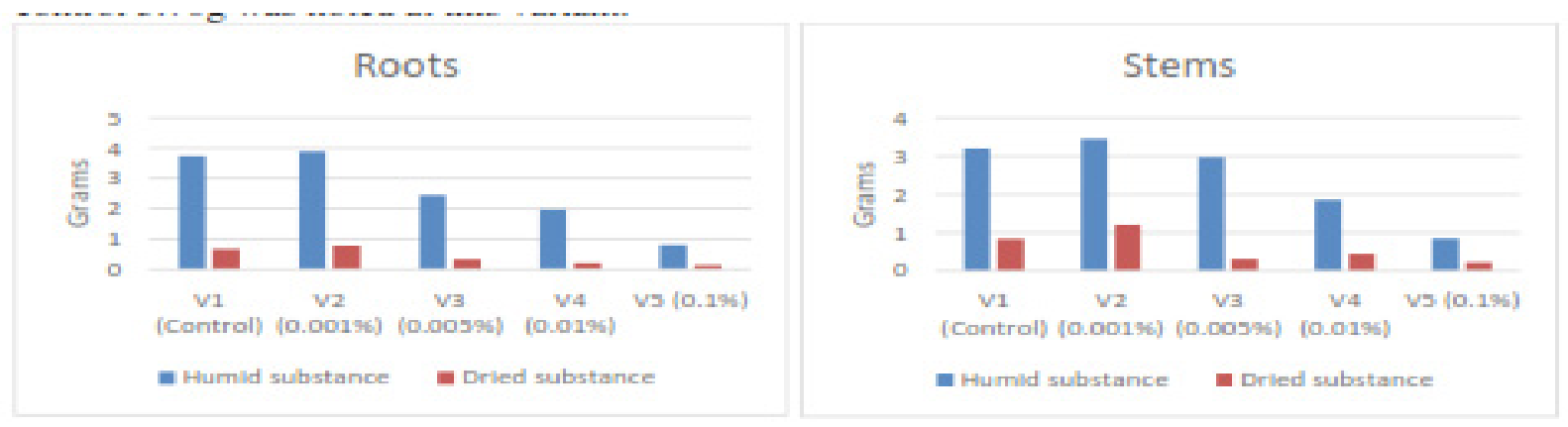

Figure 1. Humid and dried substance of bean seedlings roots and stems influenced by lead

then they were allowed to grow for 14 days, after which the amount of humid and dried substance for the root and stem was determined in each variant.

All roots were taken, grinded and put in ampules brought to constant weight. The stems were put in other ampules, obtaining 2 ampules for each variant. The ampules with fresh material were weighted and afterwards were introduced in a thermostat to be brought to constant eight. Then, average moisture and dry weight were calculated. The results were written in tables and were plotted graphic.

\section{Results and Discussions}

The obtained results showed that, in high concentrations $(0.1 \%)$, lead produces a strong inhibition of root growth (Fig.1). Reduced plant material before drying $0.80 \mathrm{~g}$, compared to the control $3.76 \mathrm{~g}$ was noted at this variant.

At this concentration, it is also observed the significant decrease of the vegetal material after drying $0.14 \mathrm{~g}$, in contrast to the control where it was $0.66 \mathrm{~g}$; this demonstrates that water with high concentration of lead acetate strongly inhibits the roots growth. As for the control, the value of the weight of the wet substance ( $3.76 \mathrm{~g}$ ) was 4 times higher than of the highest tested lead concentration. This demonstrates that the growing process is due to the presence of water in plants. Comparing the values recorded at the control before drying the vegetal material (3.76 g) with those obtained at V2 - $0.001 \%(3.89 \mathrm{~g})$ that is at the lowest lead concentration, it results the stimulating effect of this microelement by the accumulated difference of $0.13 \mathrm{~g}$. In the same figure (Fig.1) we note the analysis of water accumulation at each experimental variant for stem. At the variant V2 - $0.001 \mathrm{~Pb}$ with the lowest concentration, a small increase of humid substance (3.45 g) compared with V1 - control (3.21 g), V3 - 0.005\% (2.98 g), V4 - 0.01\% (1.85 g) and V5 - 0.1\% (0.85 g).

Similar studies were performed by Yilmaz et. al., (2009), on Solanum melongena which showed that fresh and dried biomass from vegetative organs is reduced by administering high concentrations of lead.

\section{Conclusion}

Both for root and stem, the control had high quantity of humid substance, which proves that the water contained in the vegetal material was important for the growth of these organs. At the V2 variant, where the lead concentration was $0.001 \%$, a small increase of the values was recorded, above those of the control. The most significant decrease was recorded at high concentrations V5 - 0.1\%, significant inhibition occurred on the growth of the surveyed vegetative organs.

\section{References:}

1. Boldor O, Trifu M, Raianu O (1981). Plant physiology. Didactic and Pedagogical Publishing House, Bucharest.

2. Dobrota C (2012). Plant physiology. Risoprint Publishing House, Cluj Napoca.

3. Yilmaz K, Akinci I E, Akinci S (2009). Effect of lead accumulation on growth and mineral composition of eggplant seedlings (Solarium melongena). New Zealand Journal of Crop and Horticultural Science, 37: 189-199. 